LWSA

PAPER - OPEN ACCESS

\title{
Analisis Perbedaan Tick Size dan Risiko Saham Sebelum dan Sesudah Reverse Stock Split di Bursa Efek Indonesia
}

\author{
Author : Chairunis Chairunis \\ DOI $\quad: 10.32734 /$ lwsa.v1i1.159 \\ Electronic ISSN : :2654-7058 \\ Print ISSN : 2654-7066
}

Volume 1 Issue 1 - 2018 TALENTA Conference Series: Local Wisdom, Social and Arts

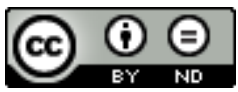

This work is licensed under a Creative Commons Attribution-NoDerivatives 4.0 International License.

Published under licence by TALENTA Publisher, Universitas Sumatera Utara
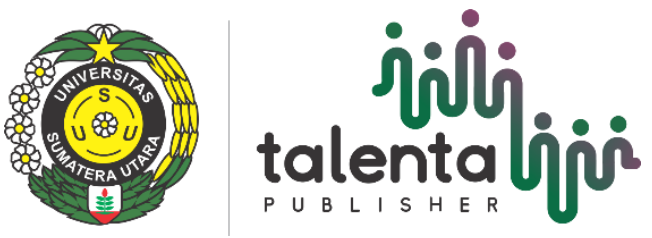


\title{
ن talenta ịị TALENTA Conference Series \\ Available online at https://talentaconfseries.usu.ac.id

\section{Analisis Perbedaan Tick Size dan Risiko Saham Sebelum dan Sesudah Reverse Stock Split di Bursa Efek Indonesia}

\author{
Chairunis $^{\mathrm{a}}$ \\ ${ }^{a}$ Fakultas Ekonomi dan Bisnis-Universitas Sumatera Utara \\ anischairunis@gmail.com
}

\begin{abstract}
Abstrak
Harga saham yang rendah sering diindikasikan sebagai kinerja yang kurang baik dari sebuah perusahaan. Harga saham tersebut dinilai kurang menarik bagi investor dan mengakibatkan menurunnya aktifitas perdagangan saham. Untuk meningkatkan aktifitas perdagangan, maka perlu dilakukan sebuah aksi korporasi, salah satunya adalah reverse stock split. Reverse stock split bertujuan mengembalikan harga saham pada kisaran wajar. Sehingga memberikan kesan bonafit dan menarik bagi investor untuk melakukan jual beli saham. Berkenaan dengan hal tersebut maka penelitian ini mencoba untuk melihat ada atau tidak perbedaan pada tick size dan risiko saham sebelum dan sesudah reverse stock split. Penelitian ini menggunakan data sekunder perusahaan yang melakukan reverse stock split di Bursa Efek Indonesia yang diperoleh dari website dan situs resmi. Metode yang digunakan dalam penelitian ini analisis komparatif. Dalam penelitian ini terdapat 21 perusahaan yang melakukan reverse stock split di Bursa Efek Indonesia pada periode 2005-2014 dengan 1 perusahaan melakukan 2 kali reverse stock split sepanjang periode pengamatan sehingga terdapat 16 sampel perusahaan yang memenuhi kriteria populasi sasaran. Hipotesis dalam penelitian ini adalah terdapat perbedaan tick size dan risiko saham sebelum dan sesudah reverse stock split. Hipotesis penelitian diuji dengan Wilcoxon Signed Rank Test menggunakan tingkat signifikansi sebesar 5\% $(0,05)$ karena data tidak berdistribusi secara normal. Hasil penelitian menunjukan bahwa terdapat perbedaan tick size sebelum dan sesudah reverse stock split dan tidak terdapat perbedaan risiko saham sebelum dan sesudah reverse stock split.
\end{abstract}

Kata Kunci: Tick Size; Risiko Saham; Reverse Stock Split

\section{Pendahuluan}

Informasi merupakan kebutuhan mendasar bagi para investor di pasar modal dalam setiap pengambilan keputusan. Ketidakpastian pergerakan harga saham tentu akan memberikan risiko kepada investor sehingga keberadaan informasi diharapkan dapat mengurangi risiko yang akan terjadi. Salah satu bentuk informasi adalah corporate action. Corporate action adalah tindakan strategis yang dilakukan oleh emiten yang secara signifikan mempengaruhi jumlah dan harga efek (saham atau obligasi) yang diterbitkan oleh emiten (Profit Buletin, 2014).

Reverse stock split merupakan salah satu dari corporate action. Menurut Martell dan Webb (2005) A reverse stock split is one in which the firm raises its stock price and reduces the number of shares outstanding. Sebagai contoh, jika sebelum melakukan reverse stock split saham PT ABC senilai Rp. 100,00 ( 500.000 lembar) setelah melakukan reverse stock split 1:5 maka harga saham menjadi Rp. 500,00 ( 100.000 lembar). 
Ada beberapa alasan yang menjadi dasar perusahaan melakukan reverse split, beberapa diantaranya adalah harga saham perusahaan yang terlalu rendah dinilai memiliki kinerja yang buruk. Dengan reverse split perusahaan berharap dapat menggerakkan harga saham pada kisaran yang optimal dan memberikan kesan bonafit. Kemudian reverse stock dinilai juga dapat mengurangi biaya transaksi saham (Lihua Jing : 2004).

Kisaran harga yang optimal dan biaya transaksi berkurang dapat dicapai apabila harga saham berada pada tick size realtif. Tick size (fraksi harga saham) adalah ukuran minimal yang diperbolehkan dalam tawar-menawar harga saham. Menurut Angel (1997) A large relative tick size provides an incentive for dealers to make markets and for investors to provide liquidity by placing limit order, despite its placing a high floor on the qouted bid-ask spread. Jadi, harga saham yang berada pada tick size relatif bertujuan untuk meningkatkan likuiditas saham

Peristiwa reverse stock split mengakibatkan jumlah saham yang beredar berubah sehingga investor yang telah terlibat dalam aktifitas reverse stock split melakukan penyusunan kembali investasinya. Penyusunan kembali tentu akan mempertimbangkan risiko saham sehingga diharapkan akan diperoleh tingkat risiko saham yang lebih kecil ( Mardiyanti dan Khasanah, 2011).

Berdasarkan uraian diatas peneliti tertarik untuk menguji apakah terdapat perbedaan tick size dan risiko saham sebelum dan sesudah reverse stock split yang terjadi pada perusahaan di Bursa Efek Indonesia.

\section{Metode Penelitian}

Berdasarkan tingkat eksplanasinya (tingkat kejelasannya) penelitian ini digolongkan sebagai penelitian komparatif. Penelitian komparatif adalah penelitian yang bersifat membandingkan. Dalam penelitian ini digunakan metodologi event study, yaitu suatu studi yang mempelajari reaksi pasar terhadap suatu peristiwa. Tujuannya adalah untuk menilai apakah terdapat perbedaan tick size dan risiko saham sebelum dan sesudah reverse stock split.

\section{Operasionalisasi Variabel:}

1. Tick size adalah ukuran minimal yang diperbolehkan untuk menentukan harga dalam tawar menawar saham. Berikut fraksi harga saham pada yang ditetapkan pada November 2012:

Tabel 1: Tick Size (Fraksi Harga Saham)

\begin{tabular}{lll}
\hline \multicolumn{3}{c}{ November 2012 } \\
\hline Kelompok Harga & Tick Size (Fraksi Harga Saham) & Max Price Movement \\
\hline$<$ Rp. 200 & Rp. 1 & Rp. 10 \\
Rp. $200-<$ Rp. 500 & Rp. 5 & Rp.50 \\
Rp. $500-<$ Rp. 2000 & Rp. 10 & Rp. 100 \\
Rp. $2000-<$ Rp. 5000 & Rp. 25 & Rp. 250 \\
$\geq$ Rp. 5000 & Rp. 50 & Rp.500 \\
\hline
\end{tabular}

Sumber: www.idx.com

2. Risiko saham sebagai variance aitu nilai deviasi kuadarat (squared deviation) dari rata-rata return saham.

$$
\begin{aligned}
& \text { returnharian }=\frac{-1}{-1} \\
& \text { Return harian }\left(\mathrm{R}_{\mathrm{it}}\right) \quad=\frac{--1}{-1}
\end{aligned}
$$


= rata-rata return harian 5 hari sebelum dan sesudah peristiwa reverse stock split

Risiko saham $=\quad-$

\section{Metode Pengumpulan Data}

Data yang digunakan adalah data sekunder. Metode pengumpulan data menggunakan metode dokumentasi dengan cara mengumpulkan data dari www.ksei.co.id, www.yahoofinance.com, www.duniainvestasi.com dan record dari data base BEI. Data yang diambil berupa:

1) Data perusahaan yang mengumumkan reverse split pada periode Januari 2005-Desember 2014.

2) Harga saham harian saat penutupan pada 6 hari sebelum dan 5 hari sesudah tanggal pelaksanaan reverse split.

3) Data Tick Size ( fraksi harga saham) pada November 2012.

\section{Populasi dan Sampel}

Target populasi dalam penelitian ini adalah perusahaan-perusahaan yang melakukan reverse stock split di Bursa Efek Indonesia dari tahun 2005 sampai dengan 2014. Metode penarikan sampel yang digunakan dalam penelitian ini adalah menetapkan populasi sasaran yang didasarkan pada kriteria-kriteria tertentu sesuai tujuan dan masalah penelitian. Kriteria yang harus dipenuhi adalah sebagai berikut:

a. Emiten melakukan reverse split pada periode Januari 2005 - Desember 2014.

b. Emiten yang tidak di delisting selama periode pengamatan.

c. Emiten tidak melakukan corporate action selain reverse split seperti pembagian dividen, saham bonus, right issue, stock split secara bersamaan baik sebelum maupun sesudah, selama periode uji.

\section{Metode Analisis Data}

Dalam penelitian ini metode yang digunakan adalah metode uji beda. Data penelitian yang berdistribusi normal akan diuji dengan paired sample $t$ test. Dan data yang tidak berdistribusi normal akan diuji dengan wilcoxon sign rank test. Uji normalitas data untuk menentukan data berdistribusi normal atau tidak menggunakan kolmogorov smirnov liliefors. Taraf signifikansi yang digunakan sebesar 5\%. Dasar pengambilan keputusan normalitas data sebagai berikut:

1. Jika probabilitas $<0,05$ maka data tidak berdistribusi normal.

2. Jika probabilitas $>0,005$ maka data berdistribusi normal.

Dasar pengambilan keputusan untuk menerima dan menolak $\mathrm{H}_{0}$ pada uji paired sample $\mathrm{t}$ test sebagai berikut:

1. Jika probabilitas $<0,05$ maka $\mathrm{H}_{0}$ ditolak, berarti terdapat perbedaan.

2. Jika probabilitas $>0,05$ maka $\mathrm{H}_{0}$ diterima, berarti tidak terdapat perbedaan.

Dasar pengambilan keputusan untuk menerima dan menolak H0 pada uji wilcoxon sign rank test sebagai berikut:

1. Jika probabilitas $<0,05$ maka $\mathrm{H}_{0}$ ditolak, berarti terdapat perbedaan.

2. Jika probabilitas $>0,05$ maka $\mathrm{H}_{0}$ diterima, berarti tidak terdapat perbedaan.

\section{Hasil dan Pembahasan}

\section{Analisis Deskriptif}


Tabel 2: Statistik deskriptif Tick Size Sebelum dan Sesudah Reverse

\begin{tabular}{|c|c|c|c|c|c|c|}
\hline & & & & & \multicolumn{2}{|c|}{ Stock Split } \\
\hline & $\mathrm{N}$ & Mean & Median & Maximum & Minimum & $\begin{array}{c}\text { Std. } \\
\text { Deviation }\end{array}$ \\
\hline \multicolumn{7}{|l|}{ Tick } \\
\hline Size & 16 & 1.266667 & 1.000000 & 5.000000 & 1.000000 & 1.032796 \\
\hline \multicolumn{7}{|c|}{ Sebelum } \\
\hline \multicolumn{7}{|l|}{ Tick } \\
\hline Size & 16 & 3.200000 & 1.000000 & 10.00000 & 1.000000 & 2.730777 \\
\hline Sesudah & & & & & & \\
\hline
\end{tabular}

Sumber: Hasil Penelitian, 2016 (Data diolah)

Tabel 2 merupakan tabel yang menggambarkan statistik deskriptif tick size pada saat sebelum dan sesudah reverse split dengan melakukan pengamatan terhadap 16 objek penelitian. Pada Tabel 2 tampak mean tick size sebelum reverse split sebesar 1.266667 dan mean tick size sesudah reverse split sebesar 3.200000. Hal ini menunjukan bahwa setelah peristiwa reverse split terjadi peningkatan pada rata-rata tick size.

Tabel 3: Statistik Deskriptif Risiko Saham Sebelum dan Sesudah Reverse Stock Split

\begin{tabular}{|c|c|c|c|c|c|c|}
\hline & $\mathrm{N}$ & Mean & Median & Maximum & Minimum & $\begin{array}{c}\text { Std. } \\
\text { Deviation }\end{array}$ \\
\hline \multicolumn{7}{|l|}{ Tick } \\
\hline Size & 16 & 0.049925 & 0.038750 & 0.152500 & 0.000000 & 0.047570 \\
\hline \multicolumn{7}{|c|}{ Sebelum } \\
\hline \multicolumn{7}{|l|}{ Tick } \\
\hline Size & 16 & 0.075388 & 0.059050 & 0.177900 & 0.007400 & 0.053763 \\
\hline Sesudal & & & & & & \\
\hline
\end{tabular}

Sumber: Hasil Penelitian, 2016 (Data diolah)

Tabel 3 merupakan tabel yang menggambarkan statistik deskriptif risiko sahampada saat sebelum dan sesudah reverse split dengan melakukan pengamatan terhadap 16 objek penelitian. Pada Tabel 3 tampak mean risiko saham sebelum reverse split sebesar 0.049925 dan mean risiko saham sesudah reverse split sebesar 0.075388 . Hal ini menunjukan bahwa setelah peristiwa reverse split terjadi peningkatan pada rata-rata risiko saham.

\section{Uji Normalitas Data}

Sebelum melakukan pengujian hipotesis maka akan dilakukan pengujian normalitas data. Pengujian normalitas data dilakukan dengan Uji Kolmogorov Smirnov Liliefors dengan penilaian jika data menghasilkan probabilitas signifikansi diatas $5 \%(0,05)$ maka data tersebut terdistribusi normal dan sebaliknya apabila data menghasilkan probabilitas signifikansi dibawah 5\% $(0,05)$ maka data tersebut tidak terdistribusi normal. Data yang tidak terdistribusi normal selanjutnya akan diuji perbedaan sebelum dan sesudah peristiwa dengan menggunakan Uji Wilcoxon.

Tabel 4: Uji Normalitas Data Kolmogorov-Smirnov Liliefors Tick Size Sebelum Reverse Stock Split

\begin{tabular}{lrrr}
\hline Method & Value & Adj. Value & Probability \\
\hline Lilliefors (D) & 0.535207 & NA & 0.0000
\end{tabular}




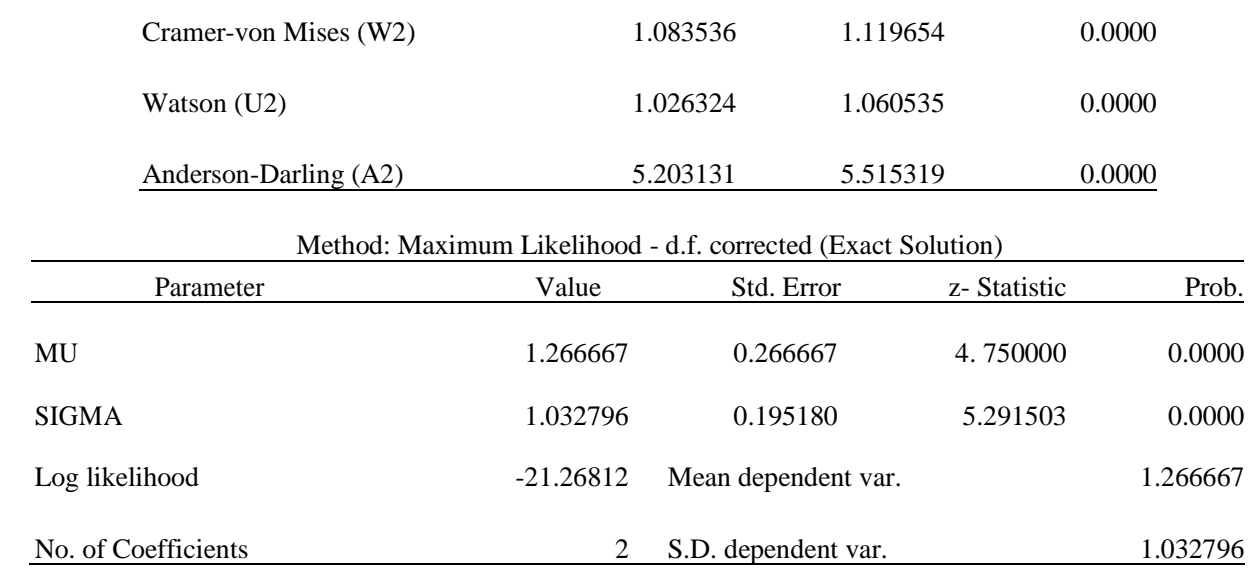

Tabel 4 menjelaskan bahwa tick size sebelum reverse stock split adalah tidak berdistribusi normal dengan probabilitas signifikansi tick size sesudah reverse split adalah 0,0000. Probalitas signifikansi ini lebih kecil dari taraf nyata 5\% $(0,05)$. Dengan demikian pengujian hipotesis pada tick size saham menggunakan Uji Wilcoxon.

Tabel 5: Uji Normalitas Data Kolmogorov-Smirnov Liliefors Tick Size Sesudah Reverse Stock Split

\begin{tabular}{|c|c|c|c|c|}
\hline Method & Value & Adj. Value & \multicolumn{2}{|l|}{ Probability } \\
\hline Lilliefors (D) & 0.323106 & NA & \multicolumn{2}{|l|}{0.0002} \\
\hline Cramer-von Mises (W2) & 0.297040 & 0.306941 & \multicolumn{2}{|l|}{0.0003} \\
\hline Watson (U2) & 0.288688 & 0.298311 & \multicolumn{2}{|l|}{0.0001} \\
\hline Anderson-Darling (A2) & 1.735951 & 1.840108 & \multicolumn{2}{|l|}{0.0001} \\
\hline \multicolumn{5}{|c|}{ Method: Maximum Likelihood - d.f. corrected (Exact Solution) } \\
\hline Parameter & Value & Std. Error & z- Statistic & Prob. \\
\hline MU & 3.200000 & 0.705084 & 4. 538469 & 0.0000 \\
\hline SIGMA & 2.730777 & 0.516068 & 5.291503 & 0.0000 \\
\hline Log likelihood & -35.85287 & \multicolumn{2}{|c|}{ Mean dependent var. } & 3.200000 \\
\hline No. of Coefficients & 2 & \multicolumn{2}{|c|}{ S.D. dependent var. } & 2.730777 \\
\hline
\end{tabular}

Tabel 5 menjelaskan bahwa tick size sebelum reverse stock split adalah tidak berdistribusi normal dengan probabilitas signifikansi tick size sesudah reverse split adalah 0,0002. Probalitas signifikansi ini lebih kecil dari taraf nyata 5\% (0,05). Dengan demikian pengujian hipotesis pada tick size saham menggunakan Uji Wilcoxon.

Tabel 6: Uji Normalitas Data Kolmogorov-Smirnov Liliefors Risiko Saham Sebelum Reverse Stock Split

\begin{tabular}{lccc}
\hline Method & Value & Adj. Value & Probability \\
\hline Lilliefors (D) & 0.218708 & NA & 0.0394 \\
Cramer-von Mises (W2) & 0.123539 & 0.127399 & 0.0477 \\
Watson (U2) & 0.113756 & 0.117311 & 0.0491
\end{tabular}




\begin{tabular}{|c|c|c|c|c|}
\hline Anderson-Darling (A2) & 0.712827 & 0.752506 & 0.0502 & \\
\hline \multicolumn{5}{|c|}{ Method: Maximum Likelihood - d.f. corrected (Exact Solution) } \\
\hline Parameter & Value & Std. Error & z-Statistic & Prob. \\
\hline MU & 0.049925 & 0.011892 & 4. 198053 & 0.0000 \\
\hline SIGMA & 0.047570 & 0.008685 & 5.477226 & 0.0000 \\
\hline Log likelihood & 26.52594 & Mean dependent var. & & 0.049925 \\
\hline No. of Coefficients & 2 & S.D. dependent var. & & 0.047570 \\
\hline
\end{tabular}

Tabel 6 menjelaskan bahwa risiko saham sebelum reverse stock split adalah tidak berdistribusi normal dengan probabilitas signifikansi risiko sahamsesudah reverse split adalah 0,0394. Probalitas signifikansi ini lebih kecil dari taraf nyata 5\% (0,05). Dengan demikian pengujian hipotesis pada tick size saham menggunakan Uji Wilcoxon.

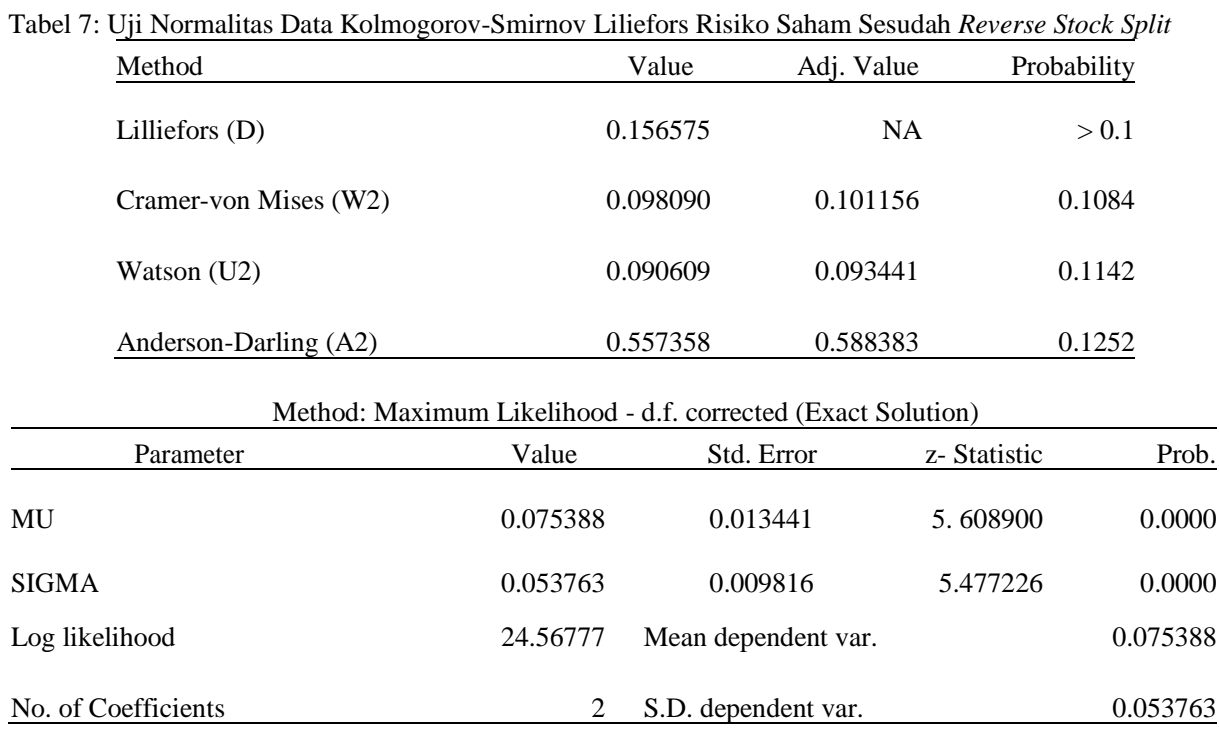

Tabel 7 menjelaskan bahwa risiko saham sesudah reverse stock split adalah berdistribusi normal dengan probabilitas signifikansi risiko sahamsesudah reverse split adalah $>0,01$. Probalitas signifikansi ini lebih besar dari taraf nyata 5\% (0,05). Sedangkan pada Tabel 6 menunjukan risiko saham tidak berdistribusi normal. Apabila salah satu probabilitas signifikansi berada di bawah taraf nyata, maka data ini dinyatakan tidak berdistribusi secara normal. Dengan demikian pengujian hipotesis pada risiko saham menggunakan Uji Wilcoxon.

\section{Uji Hipotesis}

Pengujian hipotesis dilakukan untuk melihat ada atau tidaknya perbedaan tick size dan risiko saham sebelum dan sesudah reverse stock split.

Tabel 8: Uji Wilcoxon Signed Rank Pada Tick SizeSebelum dan Sesudah Reverse Stock Split Sample Median $=0.000000$

\begin{tabular}{lll}
\hline Method & Value & Probability \\
\hline
\end{tabular}




\begin{tabular}{|c|c|c|c|}
\hline Sign (exact binomial) & & 7 & 0.0156 \\
\hline Sign (normal approximation) & & 2.267787 & 0.0233 \\
\hline Wilcoxon signed rank & & 2.439471 & 0.0147 \\
\hline van der Waerden (normal scores) & & -2.513333 & 0.0120 \\
\hline \multicolumn{4}{|l|}{ Median Test Summary } \\
\hline Category & Count & Mean Rank & \\
\hline Obs $>0.000000$ & 0 & NA & \\
\hline Obs $<0.000000$ & 7 & 4.00000000 & \\
\hline Obs $=0.000000$ & 8 & & \\
\hline Total & 15 & & \\
\hline
\end{tabular}

Pada Tabel 8 menunjukan bahwa tick size sebelum dan sesudah reverse stock split setelah diuji dengan Wilcoxon Signed Rank Test diperoleh nilai signifikansi sebesar 0,0147. Nilai signifikansi lebih kecil dari nilai taraf nyata yang telah ditetapkan yaitu sebesar 5\% $(0,05)$. Hal ini mengindikasikan $\mathrm{H}_{0}$ ditolak dan $\mathrm{H}_{\mathrm{a}}$ diterima yang berarti terdapat perbedaan tick size sebelum dan sesudah reverse stock split.

\begin{tabular}{|c|c|c|c|}
\hline Method & & Value & Probability \\
\hline Sign (exact binomial) & & 11 & 0.2101 \\
\hline Sign (normal approximation) & & 1.250000 & 0.2113 \\
\hline Wilcoxon signed rank & & 1.266865 & 0.2052 \\
\hline van der Waerden (normal scores) & & -1.339236 & 0.1805 \\
\hline \multicolumn{4}{|l|}{ Median Test Summary } \\
\hline Category & Count & Mean Rank & \\
\hline Obs $>0.000000$ & 5 & 8.60000000 & \\
\hline Obs $<0.000000$ & 11 & 8.45454545 & \\
\hline Obs $=0.000000$ & 0 & & \\
\hline Total & 16 & & \\
\hline
\end{tabular}

Pada Tabel 9 menunjukan bahwa risiko saham sebelum dan sesudah reverse stock split setelah diuji dengan Wilcoxon Signed Rank Test diperoleh nilai signifikansi sebesar 0,2052. Nilai signifikansi lebih besar dari nilai taraf nyata yang telah ditetapkan yaitu sebesar $5 \%(0,05)$. Hal ini mengindikasikan $\mathrm{H}_{0}$ diterima dan $\mathrm{H}_{\mathrm{a}}$ ditolak yang berarti tidak terdapat perbedaan risiko saham sebelum dan sesudah reverse stock split.

\section{Penutup}

Dari analisis perbedaan tick size dan risiko saham sebelum dan sesudah reverse stock split di Bursa Efek Indonesia periode 2005-2014, diperoleh beberapa kesimpulan sebagai berikut: 
1. Hipotesis pertama diuji dengan Wilcoxon Signed Rank Test menyimpulkan bahwa terdapat perbedaan tick size sebelum dan sesudah dilakukannya peristiwa reverse stock split.

2. Hipotesis kedua diuji dengan Wilcoxon Signed Rank Test menyimpulkan bahwa tidak terdapat perbedaan risiko saham sebelum dan sesudah dilakukannya peristiwa reverse stock split.

\section{References}

[1] Angel, James. J, 1997. - Tick Size, Share Price And Stock Splitll, The Journal Of Finance, Vol. 2, No. 52, pp 655-681.

[2] Lihua, Jing, 2003. - AnEven Study Of Reverse Stock Split In Hongkong Market. Working Paper, SSRN 393222, University Of Hongkong.

[3] Mardiyanti, Umi dan Khusfatun Khasanah, 2011. - Studi Komparatif Harga, Likuiditas dan Risiko Saham Sebelum dan Sesudah Perusahaan Melakukan Stock Split dan Reverse Stock Split di Bursa Efek Indonesia Tahun 2004-2009 || Jurnal Riset Manajemen Sains (JRMSI), Vol. 2, No. 1 hal 73-94.

[4] Profits Buletin, 2014, Aksi Korporasi, Volume XIII pp 1-3.

[5] www.duniainvestasi.com

[6] www.britama.com

[7] www.ksei.co.id

[8] www.sahamok.com

[9] www.yahoofinance.com 